\title{
The Political Economy of Regionalism
}

\author{
Sanjeev Goyal ${ }^{*} \quad$ Klaas Staal $^{\dagger}$
}

23 December, 1999.

\begin{abstract}
We examine the incentives of regions in a country to unite or to separate. We find that smaller regions have greater incentives to unite, relative to larger regions. We show, however, that on the whole, majority voting on separation and union generates excessive incentives to separate. This leads us to examine the scope of alternative political institutions and rules in overcoming the potential inefficiency. Our paper also provides a wide range of examples to illustrate the different institutions used in actual practice to resolve such problems.
\end{abstract}

Key Words: referendum, secession, union, voting.

JEL Numbers: D7, H2, H7.

${ }^{*}$ Econometric Institute, Erasmus University, 3000 DR Rotterdam, Netherlands. E-mail: goyal@few.eur.nl

${ }^{\dagger}$ Tinbergen Institute, Erasmus University, 3000 DR Rotterdam, The Netherlands. E-mail: staal@few.eur.nl

We thank Robert Dur for helpful comments. The paper has been presented at Erasmus and Indian Statistical Institute, Delhi. We thank the participants for useful comments. 


\section{Introduction}

During the last fifty years, the number of nations has increased dramatically from 74 in 1946 to 193 in 1997. Many of these countries were born out of the decolonization process in Africa and in the rest of the world. Moreover, in this era more than twenty boundaries between nations were changed, without creating or eliminating a nation. ${ }^{1}$ More recently, referenda have been held in many countries and these have resulted in substantial changes in political structure (as in Northern Ireland, Scotland and Wales in Great Britain and East Timor in Indonesia). At the same time, we are witnessing a move towards greater integration in Europe, which is accompanied by lowering of boundaries between countries.

In this paper, we study the role of the size of regions in determining the incentives for separation and unification. The main questions we address are as follows:

- Do smaller regions have the same incentives for union as compared to larger regions and are incentives for union and separation reflecting socially desirable outcomes?

- How do political rules influence the incentives for union and separation under majority voting?

When the regions differ much in size it is possible that in a union the large region dominates or colonizes the small region. We will examine if such unequal or unconditional union can be in the interests of the different regions. This is related to the question if one should expect union of unequal size regions or equal size regions.

To determine the influence of size on the incentives for separation we set up the following simple model. There are two regions, with one region being larger than the other. ${ }^{2}$ We assume that the regions have the same density of population. Thus size can be interpreted in terms of population or in terms of area. These regions can choose to be independent countries or to unite, by majority voting.

\footnotetext{
${ }^{1}$ See The Times Atlas [1993, Plate 8] for a survey map on border changes and changes in sovereignty since 1945 .

${ }^{2}$ The notion of regions we use is quite general. We believe that similar considerations would also apply to other political jurisdictions. To keep the text as readable as possible we will use the terms nations and countries throughout.
} 
In each region, a referendum is held on union and separation. If a majority in both regions prefers union then the outcome is union, and so there is one country. If both regions vote for separation then there will be two countries. So in case of disagreement, the two regions separate, i.e. the status quo outcome is separation.

After the decision on unification and separation the individuals in the region choose the type/location of government they want to have. This determines, for example, where the capital, the national airport, the universities and other facilities are located. The model is than interpreted in a geographic dimension. The individuals living close to the capital then have the highest payoff. Seccesionist activitities will therefore take place at the fringe of the nation: the individuals at the fringe of a nation will live closer to the capital if the nation breaks up.

The model also has an interpretation in a preference dimension. Individuals who are close to each other are assumed to have the same preferred type of government. Governments located far from individuals differ more from the preferred type of government of these individuals than from the preferred type of government of the individuals who are located in close proximity of the government. The choice of the type of government, for example, can determine which social security system will prevail. The people who live close to the capital or equivalently, who prefer the prevailing social security system, have a higher payoff than other individuals.

In the basic model the costs of having a government are supposed to be fixed: they do not depend on the size of a nation and factors like economic development and economic integration. The fixed cost assumption leads up to the following basic trade-off. When a region is smaller, the people in this region are more likely to have their preferred type of government. Since the costs of government are fixed, independent of the size of the country, the tax rates will be higher in a smaller nation than in a larger nation. When the people choose for union with the other region, they will also pay less taxes but it is also less likely that they have their preferred type of government.

In our model, the increase in the payoff of an individual of being closer to the public good is linear. The tax advantage for the smaller region from union is, however, strictly decreasing and convex in its own size. For very small regions, the tax advantage is clearly enormous and dominates the loss in political influence. The large region faces the reverse trade-offs: the tax advantages of union are 
increasing in the size of the smaller region. Moreover, they are also convex in the size of the smaller region. This implies that when the smaller region is very small then it is likely that the tax advantages are offset by the political costs. Thus the large region prefers a union with relatively large other regions only. These observations have the following implication: very small regions will have major incentives to merge, but the marginal tax gain for the large region is relatively minor and no union will take place, if the regions are very unequal in size. Thus, union will only occur between regions which have approximately the same size.

We show that the incentives for union and separation under majority voting do not reflect social welfare accurately. This means that under majority voting the aggregate welfare is not maximized. Individuals in the large region who are located far from the small region have an incentive to separate to get the public goods closer to their preferences. The individuals who are located close to the other region have an incentive for union, but in case of separation they should also pay more taxes. The costs of separation are thus not borne exclusively by the individuals who are in favour of separation. Hence there exists excessive incentives for separation: under majority voting there will be more countries than socially desirable. This leads us to study alternative political institutions that may help mitigate the inefficiency.

We next examine the role of status quo in determining the nature of voting equilibrium. It is possible that the regions which are voting on union and separation initially form a union. It is then appropriate to have separation solely when both regions prefer separation. ${ }^{3}$ When we apply this condition, there are still, although less, excessive incentives for separation. The decision on union and separation can also be taken in one referendum in which individuals of both regions participate, i.e. in a nationwide referendum. We find that the outcome under a nationwide referendum is the same as in the case where separation only takes place when both regions agree on separation. This analysis suggests that the finding that majority voting leads to too much separation is robust.

Finally, we examine the prospects of unequal union. If there are only a few individuals in the small region then the tax burden will be very high. One way out would be for the small region to accept unequal or unconditional union. In

\footnotetext{
${ }^{3}$ We may interpret a national parliament deciding on break up of a nation as analogous to a nationwide referendum on union and separation.
} 
this case only the large region determines the location or type of the public good. This implies that unequal union takes place when regions differ very much in size. This gives a simple explanation for why small islands Montserrat in the Caribean and Bermuda in the Pacific might prefer to remain crown colonies of the United Kingdom. ${ }^{4}$

Our paper is a contribution to the study of country formation and secession. There has been renewed interest in such issues in recent years, see e.g. Alesina and Spolaore [1997], Bolton and Roland [1997], Casella and Feinstein [1990] and Wei $[1991 \mathrm{a}, 1991 \mathrm{~b}]^{5}$ In particular, our paper is closely related to the paper by Alesina and Spolaore [1997] and Wei [1991a, 1991b].

Alesina and Spolaore [1997] study the equilibrium determination of the number (and size) of countries in different political regimes, in different economic environments and under varying levels of economic integration. They use the same trade-off as we use. The economic advantages of unification are compared with the political costs of a fixed-costs public good which is less close to the preferences of local majorities. In this setting, they find that democratization leads to an inefficiently large number of countries. In their analysis, the boundaries between nations are endogenous but they restrict attention to outcomes with equal sized countries. In our paper, the focus is on the role of relative size of the different regions. The sizes of the regions are exogenously specified; we take them to be defined via non-economic factors such as cultural, geographic or ethnical differences across regions. This focus on relative region size also allows us to examine the scope of political arrangements such as unequal union.

Wei [1991] examines a model in which the size of the regions is exogenously specified. Moreover, he allows for the level of a public good in a nation to vary depending on the level of economic development and the size of the nation.

\footnotetext{
${ }^{4}$ Other examples are: small countries such as Luxembourg willing to be essentially passive members of the NATO, Liechtenstein participating in a customs union with Switzerland using the Swiss franc as its national currency and Puerto Rico where indigenous inhabitants are US citizens but do not vote in US presidential elections.

${ }^{5}$ These recent political economy papers on nations is related to the local public good literature and of the literature on fiscal federalism. For the local public good theory, see Austin [1993], Benabou [1993,1995], Bewley [1981], Epple, Filimon and Romer [1984], Epple and Romer [1991], Fernandez and Rogerson [1994], Jehiel and Scotchmer [1995], Rubinfeld [1987], Scotchmer [1996], Stahl and Varaiya [1983] and Tiebout [1956]. For literature on fiscal ferderalism see Alesina and Spolaore [1995], Alesina, Perotti and Spolaore [1995], Musgrave [1959], Oates [1972], Persson and Tabellini [1992,1993,1994] and Wildasin [1988].
} 
The trade-off in his model is between the higher efficiency of the public good under union and the lower coordination costs under separation. Wei argued that the stage of development or degree of specialization of a region influences the decision on union and separation. The main result involving regional size is that a small region is more eager to secede from a unified nation than a large region, when secession is very costly and the economy is at low levels of development. However, as the economy develops, the small region is the first to demand national unification. Wei also argued that when separation and unification processes are costly, these processes do not always take place when the situation after the process is preferred by a majority in each region. Wei does not look at socially desirable incomes. Our analysis differs from Wei's in that we consider a fixedcosts public good and that we use a very different trade-off: we compare the efficiency gains in terms of one as against two governments with the political costs of greater distance to the government. In addition, we study the nature of socially desirable outcomes.

The paper is organized as follows. In Section 2 we present the basic model. Section 3 contains the analysis of this model, the solution to the majority voting process and the socially optimal outcome as well as a comparison of the two outcomes. In Section 4 we discuss the role of alternative political systems, while Section 5 concludes.

\section{Basic Model}

We suppose that one public good which identifies a nation (i.e. a country); we call this public good the 'government'. The range of all possible governments is normalized in the segment $[0,1]$. The location of a government is denoted by $l$. In addition, we assume that the total population has mass one and that individuals from this population are located at ideal points, which indicates their preferred government. The individuals are uniformly distributed on the segment $[0,1]$. The utility of each individual is decreasing with the distance from his government to his location (i.e. his ideal point). The distance between the ideal point of a consumer $i$ and the government in his country is denoted by $d_{i}$.

We assume that there will be either one or two countries (i.e. governments), which have a fixed (exogenous) boundary $\alpha$. The region located at the left-hand 
side of $\alpha$ is called region $\mathrm{A}$, and the region at the right-hand side of $\alpha$ is called region $\mathrm{B}$. Without loss of generality, we suppose that $0<\alpha<1 / 2$. We assume that there is a fixed cost $F$ per country, regardless of its size ${ }^{6}$. This $F$ includes for example the costs of building airports and hospitals and the costs of having a machinery of government. In the basic model every individual has the same, exogenous income $y$, and pays the lump-sum tax $t_{i} \cdot{ }^{7}$ Now, we can define the utility function for each individual $i$ :

$$
U(i)=g\left(1-a d_{i}\right)+y-t_{i}
$$

where $g$ and $a$ are two positive parameters. The parameter $g$ measures the utility of the public good when the preference distance $d_{i}$ is zero and the parameter $a$ measures the loss in utility if the government is farther away (i.e. when $d_{i}$ increases). The utility function is thus linear in the preference distance. For simplicity we assume that $a<1$. The parameter $a$ can then be interpreted as the marginal utility of a government located at a distance $d_{i}$.

We look at the socially optimal incentives for separation and unification and at the incentives for separation and unification under majority voting. In the latter case we assume that separation occurs when a majority of voters is in favour of separation in at least one region. This voting rule is realistic when the central government is too weak or does not want to prevent secession through military means. The disintegration of the former Soviet Union, for example, took place after the central government could not prevent secessions. ${ }^{8}$ The majority voting rule is also relevant when two initial independent countries are considering political integration which takes place only if it is favoured by a majority in each initial country.

\footnotetext{
${ }^{6}$ When the costs of a government depends on the size of the country, we could model the costs as $F=f+\zeta s$ where $s$ denotes the size of the country. We conjecture that, as long as $f$ is positive, our main results will carry over.

${ }^{7}$ Here we assume that individual wealth is equal in the two regions. We examine the case of unequal wealth across regions in Appendix B.

${ }^{8}$ The recent referendum in East Timor is another example of this procedure.
} 


\section{Analysis of the basic model.}

In this section we will first examine the outcomes when decision to form one or two countries is taken by majority voting and then we will derive the socially optimal number of countries.

\subsection{Majority voting.}

In this part we will examine the case when the decision to form one or two countries is taken by majority voting. Intuitively, it is clear that if $\alpha$ becomes very small then the small region (region A) will prefer union. The per capita cost of supporting an independent government, $F / \alpha$, becomes very large and the individuals in region $\mathrm{A}$ will therefore benefit a lot from unification. The individuals in region $\mathrm{B}$ will also compare the benefit of a lower tax rate under unification with the disadvantage of a change in the location of the public good under unification. This comparison depends in turn on the linearity of political costs, and the convexity of the tax advantage arising out of union. We will discuss this comparison after the proof of Proposition 1.

Our analysis of these issues is summarized in Proposition 1. We define $\alpha_{A}=$ $2 F / g a$ and $\alpha_{B}=1-2 F / g a$.

Proposition 1. There exists numbers $\alpha_{A}$ and $\alpha_{B}$ such that region $A$ prefers union if and only if $\alpha<\alpha_{A}$ while region $B$ prefers union if and only if $\alpha>\alpha_{B}$. Thus union only takes place if $\alpha_{B}<\alpha_{A}$ and $\alpha \in\left[\alpha_{B}, \alpha_{A}\right]$.

The first step in the proof is to show that the preferences of the person in the center of a region reflect the majority opinions in each region perfectly. This is the content of Lemma 1 . The reasoning behind this lemma is that when the individual in the centre of a region prefers something and when utility is linearly decreasing with respect to location by the same rate under all alternatives then a majority in the region shares the preference of the individual in the centre of that region. The majority is formed by the individuals which are located either to the left or to the right of the individual in the centre.

Lemma 1. In region $A$ (region $B$ ) there is a majority in favour of separation if the individual in the centre of that region wants separation. 
The proof of Lemma 1 can be found in the Appendix A. We now present the proof of Proposition 1.

Proof of Proposition 1: There will be a majority in favour of union in region $\mathrm{A}$ if the consumer $\alpha / 2$ prefers union:

$$
U_{I I}\left(\frac{\alpha}{2}\right)=g+y-\frac{F}{\alpha}<g\left(1-a\left|\frac{1}{2}-\frac{\alpha}{2}\right|\right)+y-F=U_{I}\left(\frac{\alpha}{2}\right)
$$

That is, if

$$
\alpha<\frac{2 F}{g a}=\alpha_{A}
$$

There is a majority in favour of union in region $\mathrm{B}$ if the consumer $(1+\alpha) / 2$ prefers union:

$$
U_{I I}\left(\frac{1+\alpha}{2}\right)=g+y-\frac{F}{1-\alpha}<g\left(1-a \frac{\alpha}{2}\right)+y-F=U_{I}\left(\frac{1+\alpha}{2}\right)
$$

That is, if

$$
\alpha>1-\frac{2 F}{g a}=1-\alpha_{A}=\alpha_{B}
$$

This completes the proof.

We now return to the discussion on the effects of a lower tax rate and the disadvantage of a larger preference distance under unification. These two effects do not influence utility in the same way. The influence of the preference distance is linear in $\alpha$ but the influence of a lower tax rate is not linear in $\alpha$. This is shown in Figures 1a-1c. Figure 1a shows the trade-off for low values of $F$, Figure 1b the trade-off for intermediate values of $F$, and Figure 1c the trade-off for high values of $F$. The expressions for the tax benefits and the distance costs for the individuals in region $\mathrm{B}$ can be derived from inequality (4). They are $F /(1-\alpha)$ and $g a \alpha / 2$, respectively.

It is straightforward to derive from inequality (2) that for region $\mathrm{A}$ the tax benefit of a change from separation to union is $F / \alpha-F$ while the distance costs are $g a / 2-g a \alpha / 2$. For low values of $\alpha$, we see in Figure 1a, 1c and 1e a large tax effect in region A. Region A therefore prefers union for low values of $\alpha$.

For region $\mathrm{B}$ we see in Figures 1a and $1 \mathrm{~b}$ that for low values of $\alpha$ the positive tax benefits under unification is not outweighed by the costs of longer preference distances under unification. Region B therefore prefers union for higher values 
Figure 1a: Majority voting outcomes, $\mathrm{F}<\mathrm{ga} / 4$

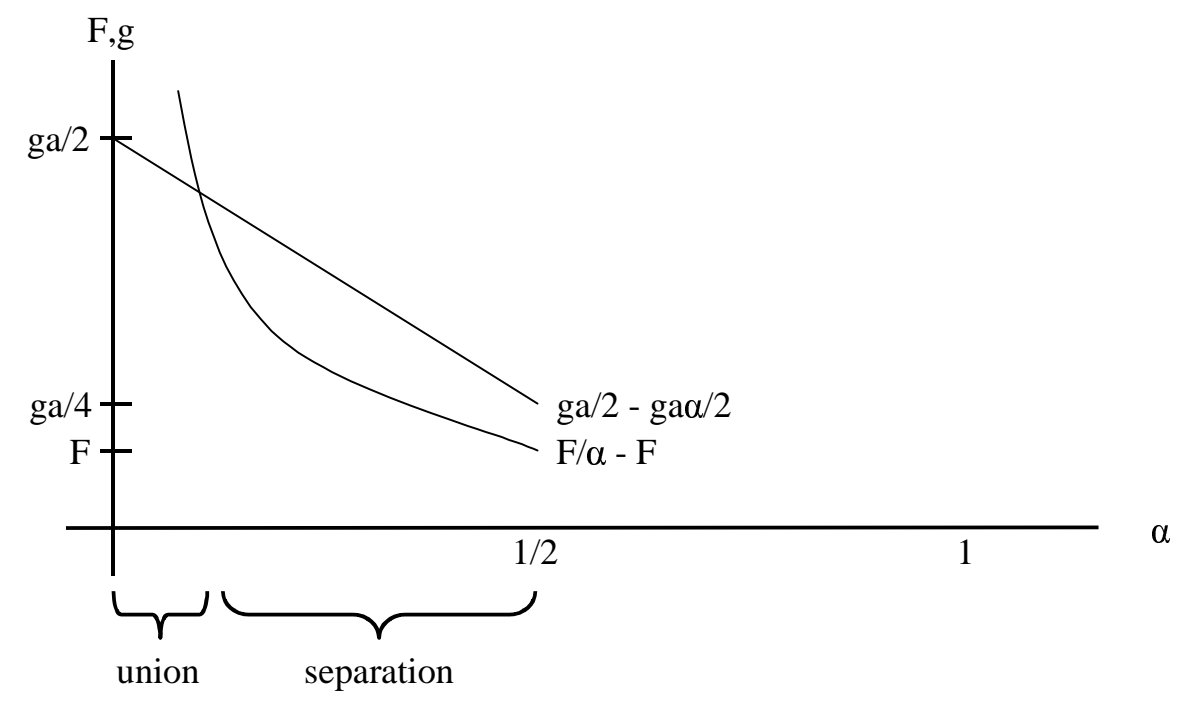

Region A

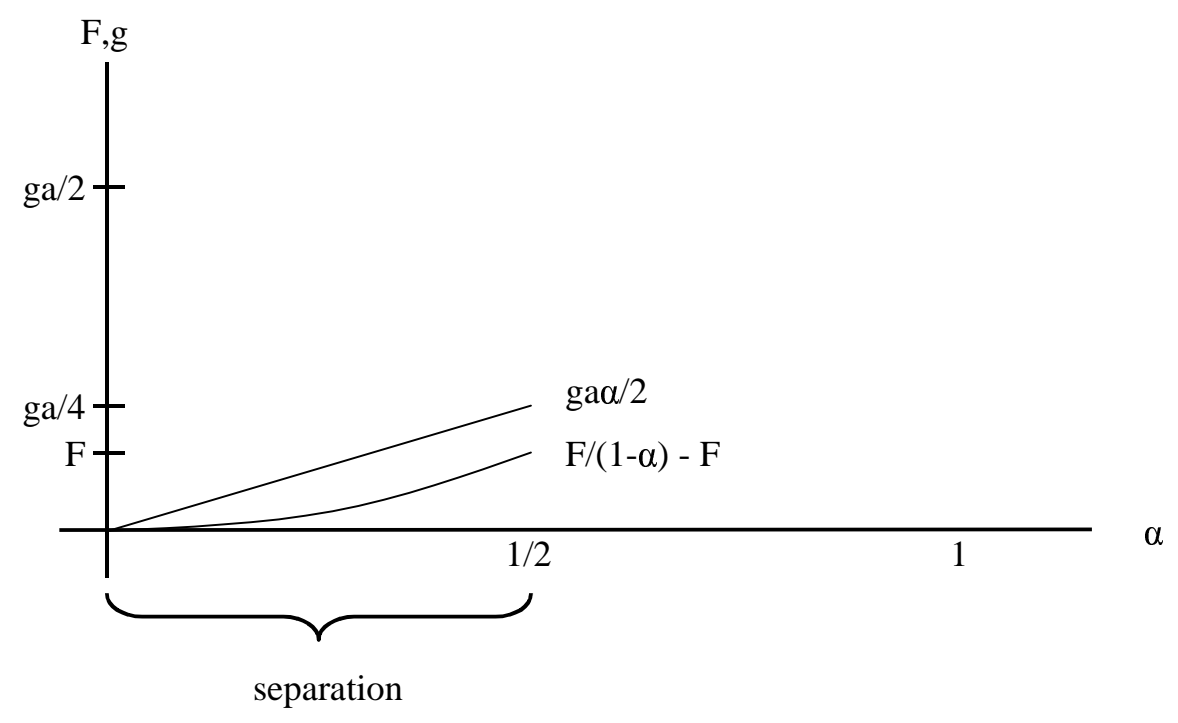

Region B 
Figure 1b: Majority voting outcomes, ga/ $4<\mathrm{F}<\mathrm{ga} / 2$
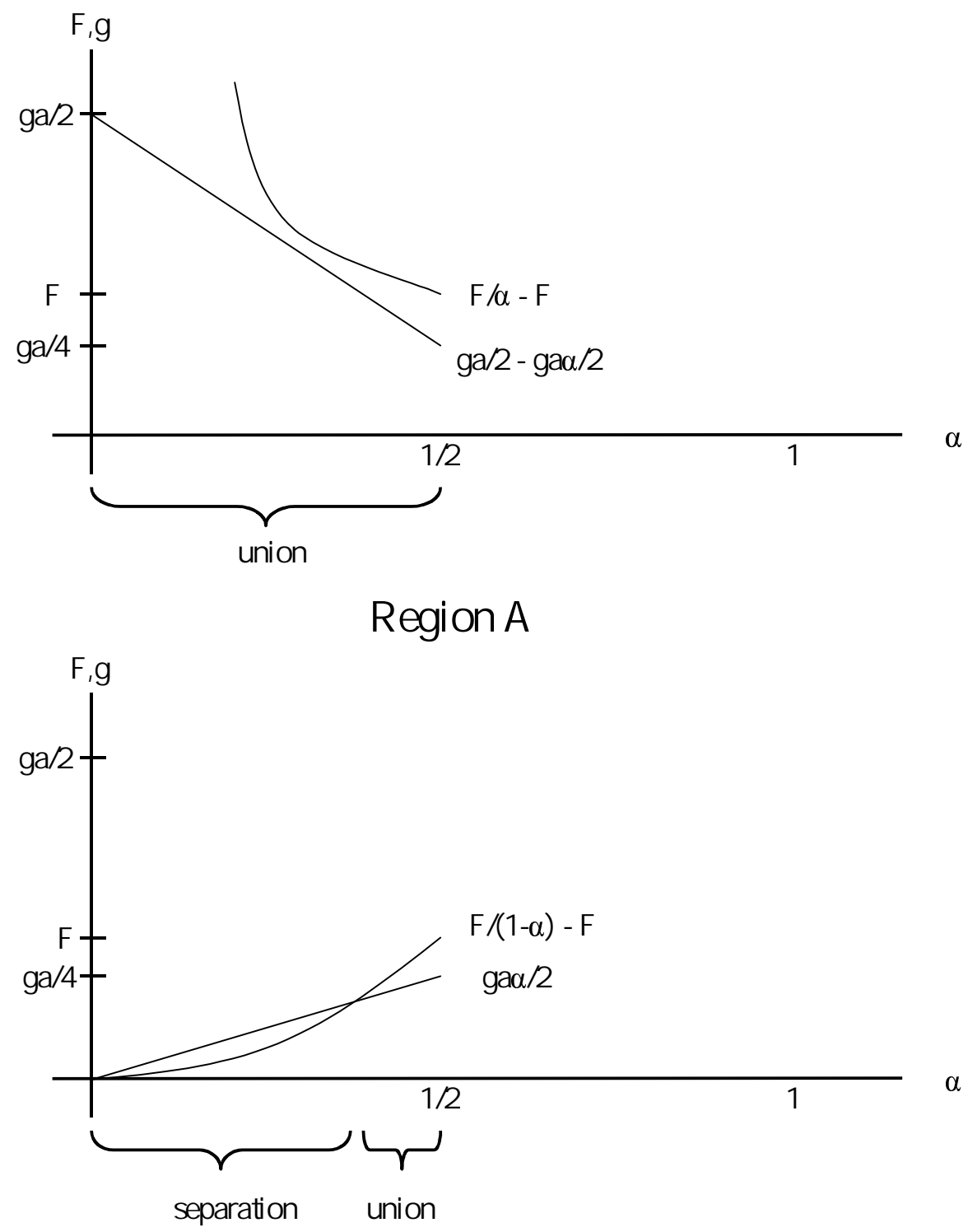

Region B 
Figure 1c: Majority voting outcomes, $\mathrm{F}>\mathrm{ga} / 2$

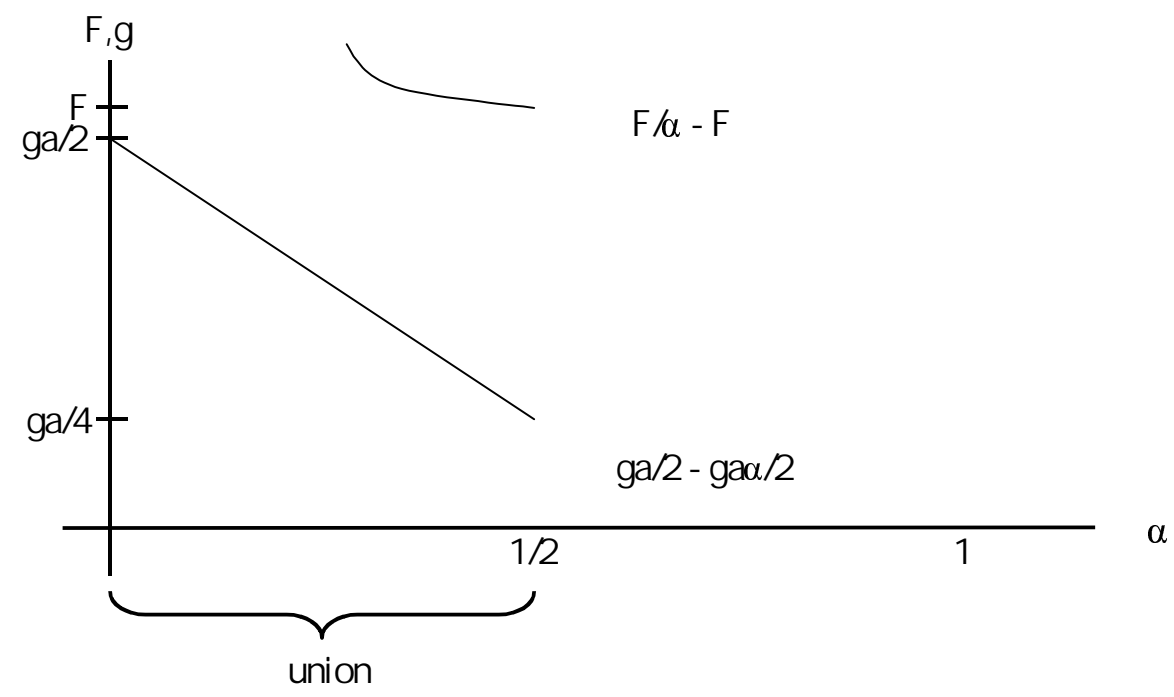

Region A

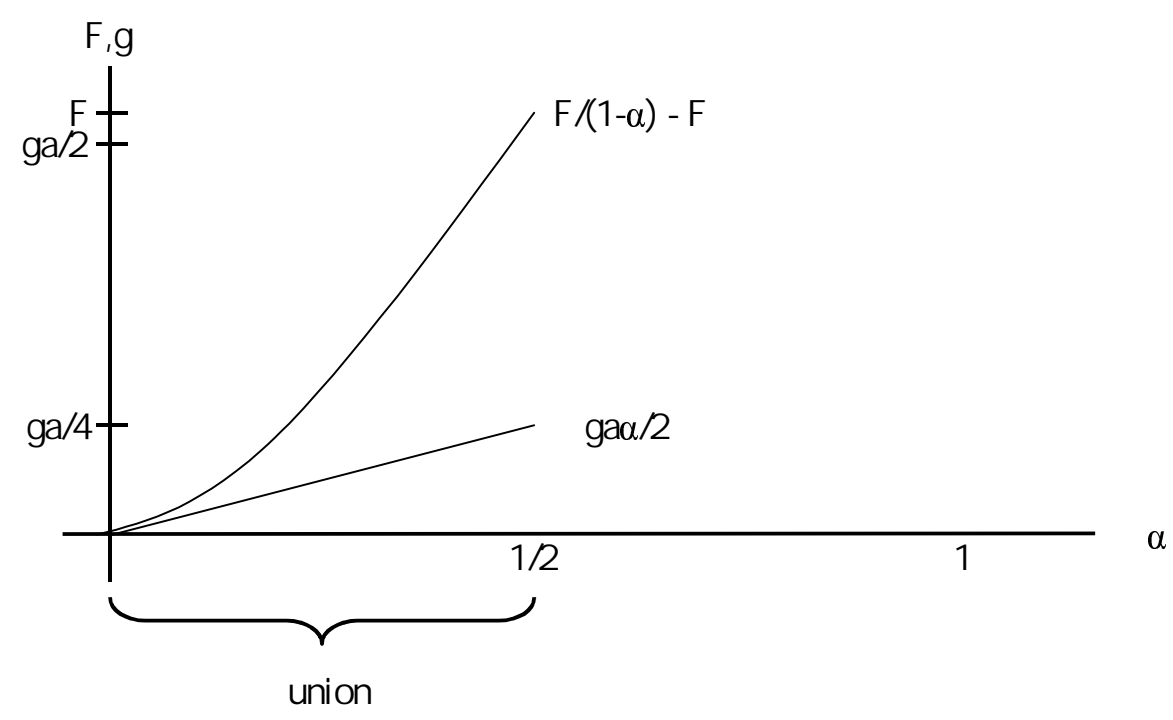

Region B 
of $\alpha$ and separation for lower values of $\alpha$. From Figure 1c it becomes clear that for high values of $F$ Region B prefers union for all values of $\alpha$ : separation is then too expensive.

We summarize the outcomes under majority voting as follows.

Proposition 2. The outcomes under majority voting are given as follows: (a) $F<g a / 4$ then there will be no union for all $\alpha \in[0,1 / 2]$ under majority voting,

(b) if $g a / 4<F<g a / 2$ then there will be union for all $\alpha \in\left[\alpha_{B}, 1 / 2\right]$ under majority voting and (c) if ga/2<F then there will be union for all $\alpha \in[0,1 / 2]$ under majority voting.

The interesting case is when $g a / 4<F<g a / 2$ since in that case union occurs for $\alpha \in[1-2 F / g a, 1 / 2]$. Note that the expression $1-2 F / g a$ is decreasing with respect to $F$. A rise in the costs of a government will therefore make union more likely. If the maximum payoff of a government $g$ increases then $1-2 F / g a$ will also increase and union becomes less likely. This also holds for an increase in the preference intensity $a$.

\subsection{The social optimum.}

In this section we characterize the socially optimal level of union and separation. It is socially optimal to have two independent nations when the increase of the total payoff outweighs the additional costs. The total payoff increases because the individuals will more likely have their preferred type of the public good. The additional costs are the fixed costs of the extra government. Therefore it is only socially optimal to have two independent nations when the fixed costs of the public good are low. When the smaller region is very small, the total additional payoff of the individuals in that region of having their own government does not outweigh the additional costs of having an extra government. Therefore it is also only socially optimal to have two independent nations when the nations do not differ too much in size.

This analysis is summarized in the next proposition. We define $F_{S P}=g a / 8$ and $\alpha_{S P}=1 / 2-\sqrt{1 / 4-2 F / g a}$.

Proposition 3. If $F>F_{S P}$ then union is the unique optimal outcome; if $F<$ $F_{S P}$ then union is optimal if and only if $\alpha<\alpha_{S P}$; separation is optimal otherwise.

The details of the calculations are given in Appendix A. 


\subsection{Majority Voting and Social Optima Compared.}

A comparison of the outcomes under majority voting and the social optima reveals:

Proposition 4. (i) if $F>g a / 2$ then union is socially optimal as well as the majority voting outcome for all $\alpha \in[0,1 / 2]$, (ii) if ga $/ 4<F<$ ga/2 then union is socially optimal for all $\alpha \in[0,1 / 2]$ but separation obtains under majority voting for all $\alpha \in[1-2 F / g a, 1 / 2]$, (iii) if ga/8 $<F<$ ga/4 then union is socially optimal for all $\alpha \in[0,1 / 2]$ but separation obtains under majority voting for all $\alpha \in[0,1 / 2]$ and (iv) if $F<g a / 8$ then union is socially optimal for all $\alpha \in[0,1 / 2-\sqrt{1 / 4-2 F / g a}]$ but separation obtains under majority voting for all $\alpha \in[0,1 / 2]$.

These results are illustrated in Figures $2 \mathrm{a}-2 \mathrm{~d}^{9}$.

The effects of changes in $F, g$ and $a$ on the the socially optimal incentives for union are the same as on the incentives under majority voting. An increase in $F$ or a decrease in $a$ or $g$ will lead to an increase of the socially optimal incentives for separation.

It follows from Proposition 4 that there exists excessive incentives for separation under majority voting: for certain parameter values majority voting obtains separation but the socially optimal solution is union. The excessive incentives appear from the fact that the costs of separation are borne equally, but the benefits of separation borne unequally. The costs of separation, $F-F / \alpha$ for the small region and $F-F /(1-\alpha)$, are borne equally by the individuals in each region because of the lump sum taxation system. The benefits of separation of an individual depend on the location of the individuals. The individuals located close to the boundary between the regions will loose the most from separation, and the individuals at the other sides of both regions gain the most from separation. The aggregate increase in the payoff of these individuals, however, is less than the aggregate decrease in the payoff of the individuals located close to the boundary between the two regions.

\footnotetext{
${ }^{9}$ Note that $F<g a / 8$ implies $2 F / g a<1 / 2-\sqrt{1 / 4-2 F / g a}$ and $1-2 F / g a>1 / 2-$ $\sqrt{1 / 4-2 F / g a}$ (and thus $2 F / g a>1-2 F / g a$ ), that $F>g a / 4$ implies $1-2 F / g a<2 F g a$ and that $F>g a / 2$ implies that $2 F / g a>1$ and $1-2 F / g a<0$ (and thus $1-2 F / g a<2 F / g a$ ).
} 


\section{Figure 2: Majority voting \& social optima}

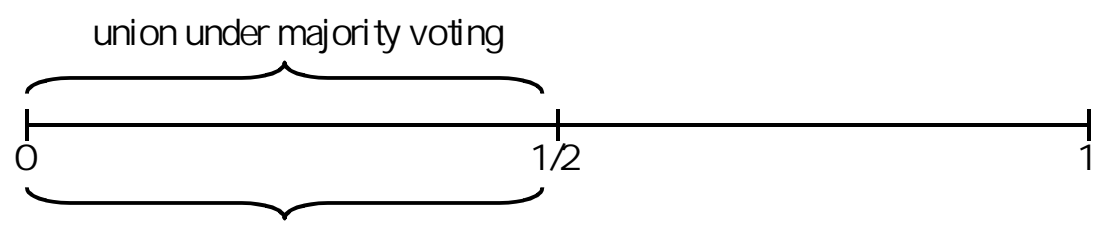

union in the social planner's solution

Figure 2a: F>ga/2

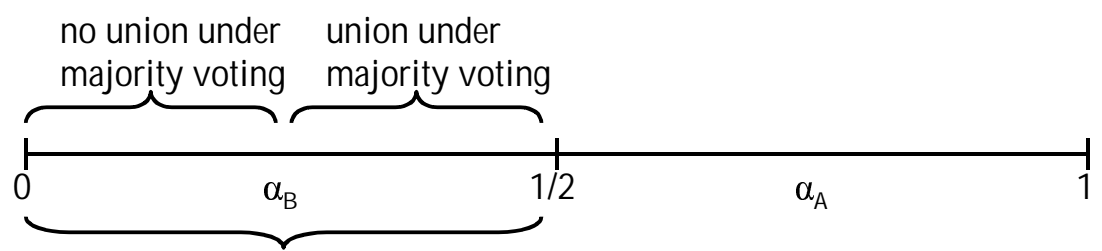

union in the social planner's solution

Figure $2 \mathrm{~b}: \mathrm{ga} / 4<\mathrm{F}<\mathrm{ga} / 2$

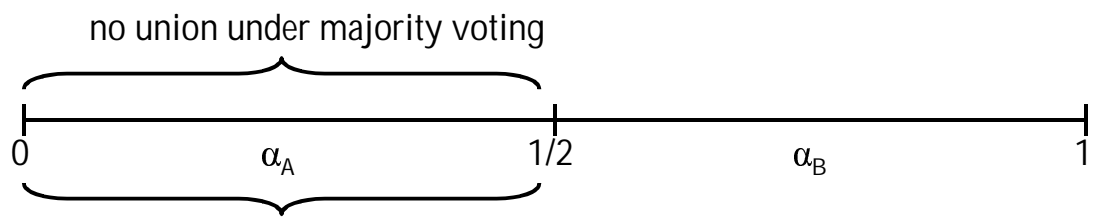

union in the social planner's solution

Figure 2c: ga/ $8<\mathrm{F}<\mathrm{ga} / 4$

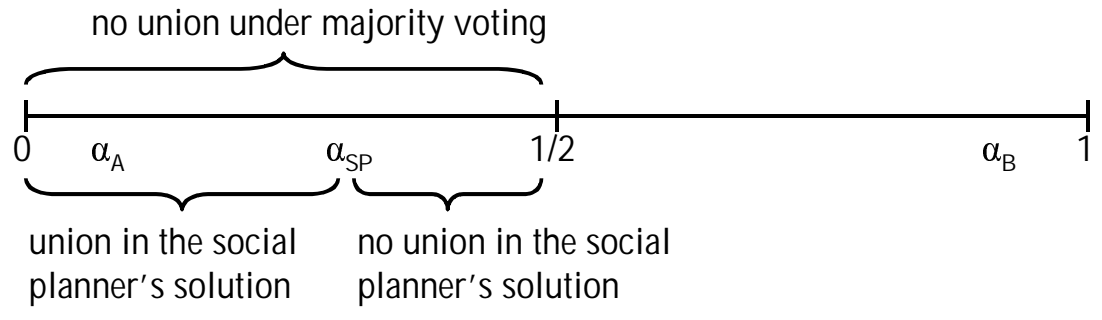

Figure 2d: F<ga/8 


\section{Alternative Political Institutions}

The previous analysis gives insight into the incentives for separation and union under majority voting. A comparison with socially optimally outcomes reveals that there exists excessive incentives for separation under majority voting. This motivates an examination of alternative political institutions which may help to mitigate such inefficiencies.

We start with considering the role of the status quo, which specifies what happens when the majority voting outcomes of both regions are different. After that we will look at what happens when just one nationwide referendum is organized to decide on union and separation. Finally, we examine the prospects for unequal union: this is an outcome in which one region gives up the influence on the location of the government, and thus on the type of the public good.

\subsection{Status quo.}

In the basic model, we apply the following majority voting rule: in each region, a referendum is organized over separation and union. When there exists a majority in favour of union in both regions then union will take place. Otherwise, both regions keep separate.

As mentioned earlier, this voting rule is realistic when in an initially unified nation, the central government is too weak or does not want prevent secession through military means. This voting rule is also relevant when two initially independent nations are considering political integration. It is obvious, however, that these conditions do not need to hold. There may, for example, exist an authoritarian regime in an initially unified nation which can stop secession supported by just one region but which can not stop secession supported by both regions. (When this authoritarian regime is strong enough to prevent secessions always, then secession will never take place. This outcome is not very interesting and will therefore be neglected in this text.) A regime in an initially unified nation may want to prevent secession because, for example, secession means loss of prestige or lower tax revenues. When such a regime exists, we can apply the following majority voting rule: in each region a referendum is organized over separation and union. When there exists a majority in favour of separation in both regions then separation will take place. Otherwise, both regions keep unified. 
The attempts of Hungary and Czechoslovakia to leave the former communistbloc, for example, was blockaded by the other nations in these bloc. Decades later, however, when the idea of secession was supported by more nations in the communist-bloc, Hungary and Czechoslovakia were allowed to leave the bloc.

The rule is also relevant when one region can prevent the other region from separation or when the constitution leads to union when both regions do not agree. A region may want to prevent secession because secession would mean unreasonably high tax rates. Aruba, an island in the Caribean Sea, for example, is still a part of the Netherlands. The Dutch constitution allows changes in the status of Aruba if the governments of Aruba and the Netherlands both agree. Although there was at least a wish by Dutch politicians for an independent Aruba, this was blocked by the island.

Under majority voting a status quo specifies what happens when the regions do not agree. For the majority voting rule used in the basic model the status quo, or default option, is separation. For the majority voting rule we will now use, the status quo will be union.

We start by observing that socially optimal outcomes do not change with a change in status quo rules: The socially optimal solution is independent of the status quo rule. Hence, the socially optimal solution in the model with union as status quo is the same as the socially optimal solution in the model with separation as status quo.

The intuition behind this is straightforward. In the social optimal solution the decision on union and separation is taken by maximizing total utility and not by considering a possible difference in preference of majorities in each region. The socially optimal solution will therefore not change.

We next observe that the necessary conditions for a majority in favour of union in a region: The conditions on $\alpha$ for having a majority preferring union in a region are the same as in Proposition 1. In fact a useful reformulation of Proposition 1 is: There exists an $\alpha_{A}$ such that a majority in region A prefers separation if and only if $\alpha>\alpha_{A}$ and there exists an $\alpha_{B}$ such that region $\mathrm{B}$ prefers separation if and only of $\alpha<\alpha_{B}$. In the proof of Proposition 1 we determined the conditions on $\alpha$ for having a majority by comparing the payoffs of the median voter under union and under separation. Using the new majority voting rule neither the median voter nor his utilities are changed, so the conditions on $\alpha$ will also be the same. 
Since we have changed the status quo from separation into union, the existence of a majority in favour of separation in both regions is crucial. Using the majority voting rule with union as status quo and using Propositions 1-3, it is easy to derive Figures 3a-3d. In the next Proposition, we give the exact conditions for the occurrence of union and separation under majority voting and the socially optimally outcomes. Propositions 1-4, in combination with the analysis from Section 3, allows us to state Proposition 5.

Proposition 5. (a) If $F>g a / 4$ then union is socially optimal as well as the majority voting outcome for all $\alpha \in[0,1 / 2]$, (b) if ga/8<F<ga/4 then union is socially optimal for all $\alpha \in[0,1 / 2]$ but separation obtains under majority voting for all $\alpha \in[2 F / g a, 1 / 2]$ and (c) if $F<g a / 8$ then union is socially optimal for all $\alpha \in[0,1 / 2-\sqrt{1 / 4-2 F / g a}]$ but separation obtains under majority voting for all $\alpha \in[2 F / g a, 1 / 2]$.

When the status quo is changed from separation into union one might expect that union becomes more likely. Indeed, union is now the majority voting outcome for more parameter values. However, a comparison of the above result with the conditions derived in our efficiency result suggest that even under this stricter political institution, excessive incentives for separation persist.

\subsection{One nationwide referendum.}

In the majority voting rules we studied until now, separate referenda were organized in each region. However, it is also possible that just one referendum is organized in an (initially) unified nation to decide on separation or union. If we interpret a national parliament deciding on break up of a nation as analogous to a nationwide referendum on union and separation then the vote on the break up of Czechoslovakia can be seen as an example of this system ${ }^{10}$.

The majority voting rule is also relevant in many different situations. For example, when the decision on separation or union is taken by a parliament with proportional representation in the unified nation. This was the case in Belgium:

\footnotetext{
${ }^{10}$ Actually there were three votes on the separation agreement: one in the Czech, one in the Slovak and one in the Czechoslovakian parliament. In all votings there was a majority in favour of separation. Our result below, Proposition 6, may be interpreted as saying that either the vote in the Czechoslovakian parliament or the two votes in the Czech and the Slovak parliaments were superfluous.
} 


\section{Figure 3: Union as status quo}

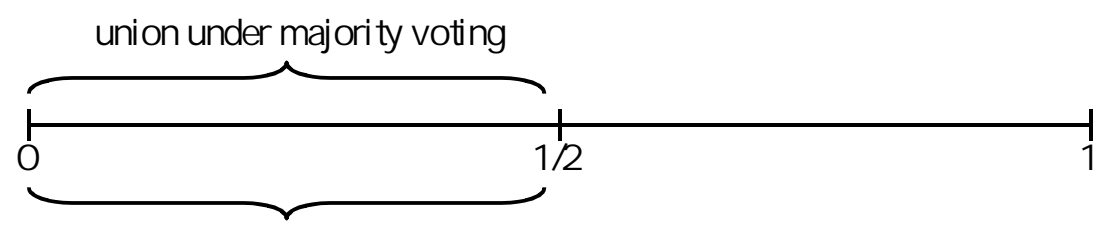

union in the social planner's solution

Figure 3a: $\mathrm{F}>\mathrm{ga} / 2$

union under majority voting

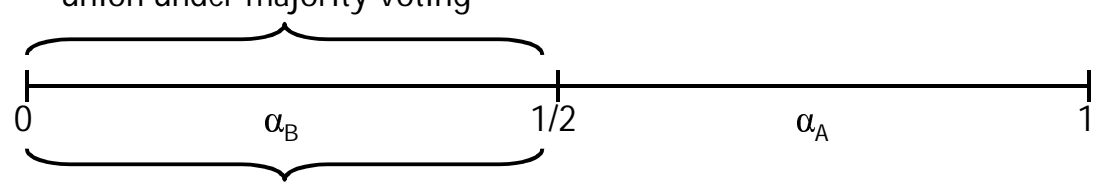

union in the social planner's solution

\section{Figure $3 \mathrm{~b}: \mathrm{ga} / 4<\mathrm{F}<\mathrm{ga} / 2$}

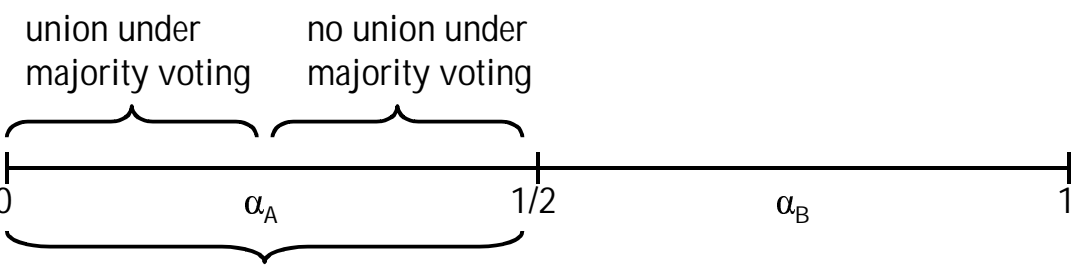

union in the social planner's solution

\section{Figure 3c: ga/ $8<\mathrm{F}<\mathrm{ga} / 4$}

union under no union under

majority voting majority voting

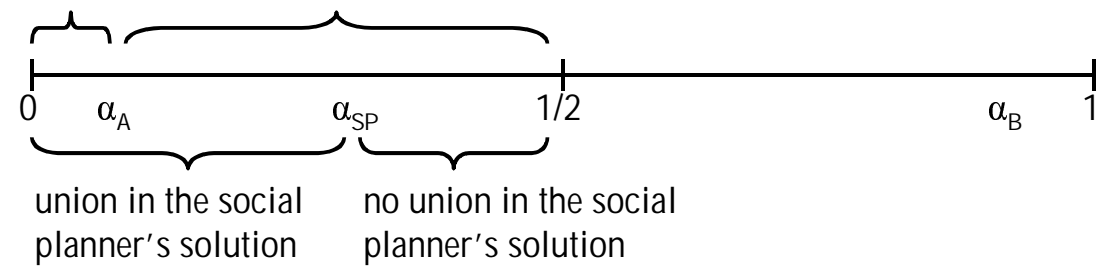

Figure 3d: F<ga/8 
the transformation from a centralized state into a federation was only possible when this transformation was supported by a majority in the parliament.

If two separate referenda are held then it will be possible that the results of these referenda are not the same. It is therefore necessary to specify a status quo, which defines what happens in that case. When we organize just one referendum, there is no need to specify a status quo, because both alternatives are now mutually exclusive.

In the following Proposition, we make clear under which condition separation is supported in one nationwide referendum.

Proposition 6. There exists a majority in favour of separation in the whole nation if and only if there exists a majority in each region in favour of separation.

Proof: A majority in each region implies that we have a majority in the whole nation, so the proof of the if-part of the statement is trivial. The proof of the only if-part of the statement is more demanding. The only if-part of the statement is equivalent to: When there does not exists a majority in favour of separation in at least one region then there does not exists a majority in favour of separation in the whole nation. There are three different cases in which there does not exist a majority in favour of separation in each region:

Case $\mathcal{A}$ There exists neither a majority in favour of separation in region $\mathrm{A}$ nor in region $\mathrm{B}$.

Case $\mathcal{B}$ There exists a majority in favour of separation in region $\mathrm{A}$ but not in region $\mathrm{B}$.

Case $\mathcal{C}$ There exists a majority in favour of separation in region $\mathrm{B}$ but not in region $\mathrm{A}$.

In case $\mathcal{A}$ it is trivial that there does not exist a majority in favour of separation in the whole nation.

Before discussing the cases $\mathcal{B}$ and $\mathcal{C}$, note that

$$
U_{I I}\left(\frac{1}{2}\right)=g-\frac{1}{2} g a \alpha+y-\frac{F}{1-\alpha}<g+y-F=U_{I}\left(\frac{1}{2}\right)
$$

Using Lemma 1, we know that case $\mathcal{B}$ implies that:

$$
U_{I I}\left(\frac{1+\alpha}{2}\right)<U_{I}\left(\frac{1+\alpha}{2}\right)
$$


because there does not exists a majority in favour of union in region $\mathrm{B}$. We also know that

$$
\frac{\partial U_{I}(i)}{\partial i}=-g a \quad \forall i \in\left[\frac{1}{2}, 1\right]
$$

This implies that $U_{I}(i)$ is decreasing in $i \in[1 / 2,(1+\alpha) / 2]$.

$$
\frac{\partial U_{I I}(i)}{\partial i}=g a \quad \forall i \in\left[\alpha, \frac{1+\alpha}{2}\right]
$$

This implies that $U_{I I}(i)$ is increasing in $i \in[1 / 2,(1+\alpha) / 2]$.

$$
\frac{\partial U_{I I}(i)}{\partial i}=-g a \quad \forall i \in\left[\frac{1+\alpha}{2}, 1\right]
$$

This implies that $U_{I I}(i)$ is decreasing in $i \in[(1+\alpha) / 2,1]$.

From expressions (7), (8) and (9) it follows that $U_{I I}(i)<U_{I}(i)$ for all $i \in[1 / 2,(1+$ $\alpha) / 2]$ and from expressions (7), (8) and (10) it follows that $U_{I I}(i)<U_{I}(i)$ for all $i \in[(1+\alpha) / 2,1]$, so $U_{I I}(i)<U_{I}(i)$ for all $i \in[1 / 2,1]$. Inequality (6) and the continuity of the utility function in $i$ imply that the individuals sufficiently close to the individual located at $1 / 2$ prefer union. Hence there does not exist a majority in favour of separation in case $\mathcal{B}$.

Using Lemma 1, we know that case $\mathcal{C}$ implies that:

$$
U_{I I}\left(\frac{\alpha}{2}\right)<U_{I}\left(\frac{\alpha}{2}\right)
$$

because there exists a majority in favour of separation in region $\mathrm{A}$. We also know that

$$
\frac{\partial U_{I}(i)}{\partial i}=g a \quad \forall i \in\left[0, \frac{1}{2}\right]
$$

This implies that $U_{I}(i)$ is increasing in $i \in[0,1 / 2]$.

$$
\frac{\partial U_{I I}(i)}{\partial i}=g a \quad \forall i \in\left[0, \frac{\alpha}{2}\right]
$$

so $U_{I I}(i)$ is increasing in $i \in[0, \alpha / 2]$,

$$
\frac{\partial U_{I I}(i)}{\partial i}=-g a \quad \forall i \in\left[\frac{\alpha}{2}, \alpha\right]
$$

so $U_{I I}(i)$ is decreasing in $i \in[\alpha / 2, \alpha]$ and

$$
\frac{\partial U_{I I}(i)}{\partial i}=g a \quad \forall i \in\left[\alpha, \frac{\alpha+1}{2}\right]
$$


so $U_{I I}(i)$ is increasing in $i \in[\alpha, 1 / 2]$.

From expressions (11), (12) and (13) it follows that $U_{I I}(i)<U_{I}(i)$ for all $i \in$ $[0, \alpha / 2]$, from expressions (11), (12) and (14) it follows that $U_{I I}(i)<U_{I}(i)$ for all $i \in[\alpha / 2, \alpha]$ and from expressions (6), (12) and (15) it follows that $U_{I I}(i)<U_{I}(i)$ for all $i \in[\alpha, 1 / 2]$, so $U_{I I}(i)<U_{I}(i)$ for all $i \in[0,1 / 2]$. Inequality (6) and the continuity of the utility function in $i$ imply that the individuals sufficiently close to the individual located at $1 / 2$ prefer union. Hence there does not exist a majority in favour of separation in the whole nation, which proves case $\mathcal{C}$.

Proposition 6 implies that when majorities in both regions prefer separation there will be two separate countries and otherwise there will be just one country. This is exactly the same outcome we got under the majority voting rule with two referenda and union as status quo. Proposition 5 therefore also holds when we apply the voting rule with one nationwide referendum. The outcomes are illustrated in Figures 3a-3d. The result on the excessive incentives for separation and union holds under nationwide referendum also: there still exist excessive incentives for separation.

\subsection{Unequal union.}

From the analysis in the basic model it follows that the smaller region (region A) wants unification when $\alpha$ is small but the larger region (region $\mathrm{B}$ ) does not want unification when $\alpha$ is small. In this case for region B the gain of unification, a lower tax rate, does not outweigh the loss by the change in the location of the public good. However, for region A the per capita cost of the public good becomes too large for low values of $\alpha$. Therefore it makes sense for region A to ask region $\mathrm{B}$ for unification under the condition that the location of the public good will be determined solely by region $\mathrm{B}$. We call this unequal or unconditional union. In this case, region A gives up their political influence in the hope of tax reduction if region $B$ accept unequal union.

There are several examples of this type of unequal union. The Dutch central bank, for example, copied accurately its monetary policy from the German Bundesbank. It can be that the costs of having an own monetary policy are too high 
for a relatively small economy ${ }^{11}$.

We begin by noting that the larger region, Region $\mathrm{B}$, will always accept unequal union: the individuals in region $B$ will then have higher utility since there is reduction in the tax rates while there is no loss of political influence. In cases where region $\mathrm{B}$ prefers equal union over separation and region $\mathrm{A}$ is willing to accept an unequal union there arises a bargaining problem. To keep matters simple, in such a case, we will assume that equal union will take place. Under these conditions, we find that the outomes are as follows:

Proposition 7. Region A prefers unequal union over separation if and only if $\alpha<\alpha_{u u}$, where $\alpha_{u u}=2 F /(g a+2 F)$.

If a majority in region A prefers unequal union then the public good will be located at $(1+\alpha) / 2$, i.e. in the centre of region B. Now, we state a Lemma helping us to determine the outcome of majority voting.

Lemma 2. In region $A$ there is a majority in favour of unequal union against the alternative of separation if the individual in the centre of region $A$ is in favour of unequal union.

The proof of Lemma 2 can be found in the Appendix A, we present the proof of Proposition 7.

Proof: Clearly, everyone in region A prefers equal union over unequal union, therefore, given Lemma 2, there will be a majority in region A for unequal union if the individual $\alpha / 2$ prefers unequal union, i.e., if

$$
U_{u u}\left(\frac{\alpha}{2}\right)=g-\frac{g a}{2}+y-F>g+y-\frac{F}{\alpha}=U_{I}\left(\frac{\alpha}{2}\right)
$$

That is, if

$$
\alpha<\frac{2 F}{g a+2 F}=\alpha_{u u}
$$

This proves Proposition 7.

The parametric restrictions required for unequal union, equal union and separation are given in Figure $4 \mathrm{a}-4 \mathrm{e}^{12}$. From the previous discussion and from the

\footnotetext{
${ }^{11}$ Another example is Monaco, which has a full customs integration with France, while its defense is the responsibility of France.

${ }^{12}$ Note that $\alpha<2 F /(g a+2 F)$ implies $F<g a \alpha /(2-2 \alpha)$ and that $g a \alpha /(2-2 \alpha)>g a / 4$
} 


\section{Figure 4: Unequal union}

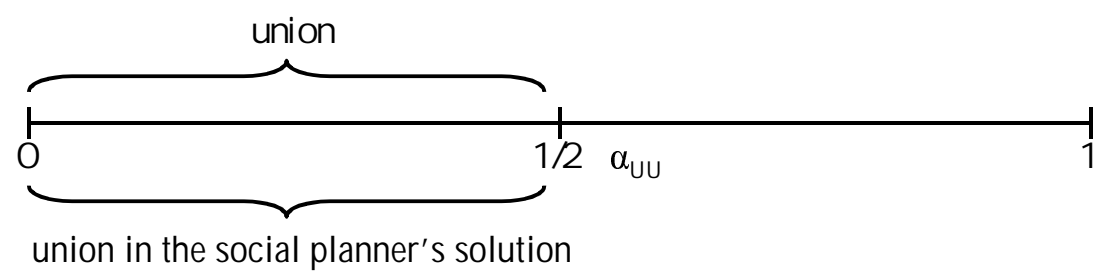

Figure 4a: $F>g a / 2$

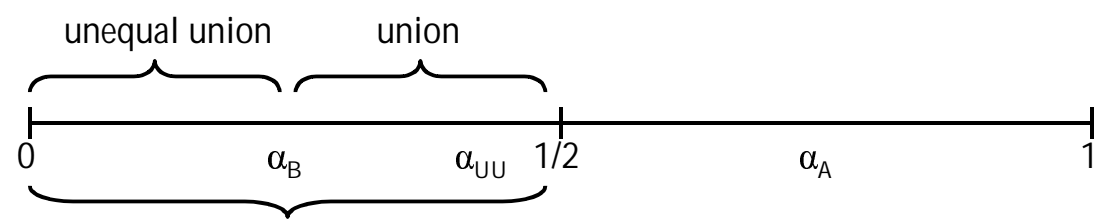

union in the social planner's solution

Figure 4b: $\operatorname{ga} \alpha /(2-2 \alpha)<\mathrm{F}<\mathrm{ga} / 2$

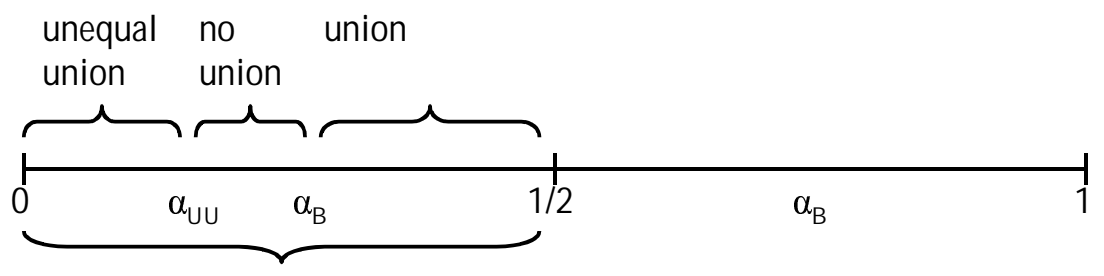

union in the social planner's solution

Figure 4c: ga/4<F< $<a \alpha /(2-2 \alpha)$ 


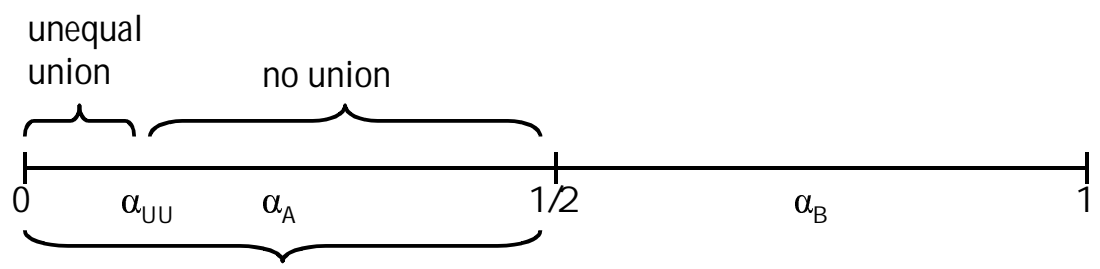

union in the social planner's solution

\section{Figure 4d: ga/ $8<\mathrm{F}<\mathrm{ga} / 4$}

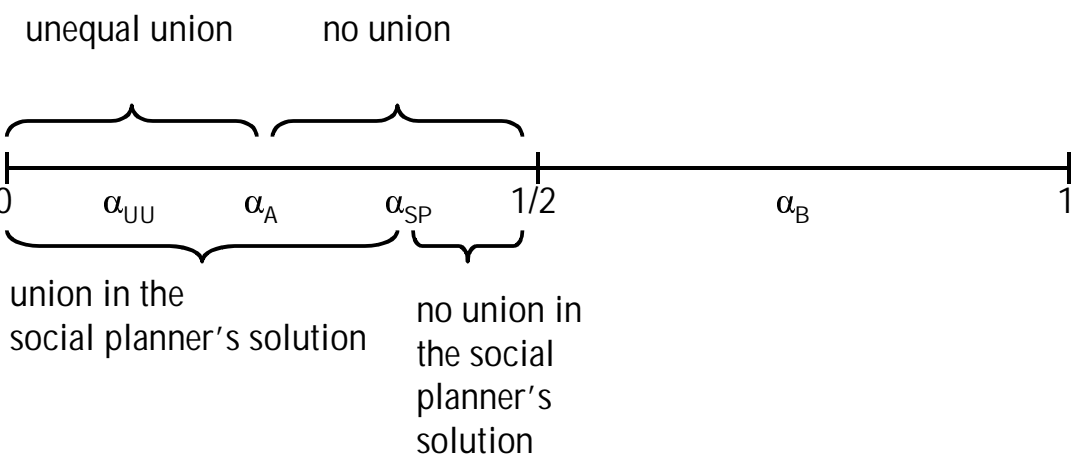

Figure 4e: F<ga/8 
Figures it is clear that for certain parameter values unequal union is preferred over separation by the smallest region. Unequal union then softens the negative consequences of excessive separation under majority voting. As one might expect, there will be unequal union when there is a large difference in size between the regions.

We note that the nature of efficient outcomes remains the same: The socially optimal solution in the model extended with unequal union is the same as the socially optimal solution in the basic model. The argument for this is that in a socially optimal solution it is already possible in the basic model to locate the public good anywhere.

\section{Conclusion}

We have examined the incentives of regions to separate or to remain united. We suppose that there is a fixed costs associated with having an independent country. In each country there are persons with different preferences about the nature of government and a larger country contains greater diversity of opinions concerning government policy. These assumptions generate a trade-off: in a smaller country the citizens have to pay higher taxes to support their government but it is more likely that the government is closer to the people. We have explored the impact of the size of different regions in shaping this trade-off.

We find that small regions have greater incentives for union, as compared to large regions. However, on the whole, majority voting generates excessive incentives for separation. This motivates an examination of different institutions that are used in practice. One arrangement we explore is the possibility of unequal union: this is an outcome in which one region agrees to hand over all political influence to the other region in return for the benefit of sharing the government and thus paying lower taxes. We find that such unequal union may be in the interests of different regions and also welfare enhancing.

\section{Appendix A.}

Proof of Lemma 1: The utility function of an individual $i$ under unification is 
given by:

$$
U_{I}(i)=g\left(1-a\left|\frac{1}{2}-i\right|\right)+y-F
$$

and under separation it is given by:

$$
U_{I I}(i)=g\left(1-a\left|\frac{\alpha}{2}-i\right|\right)+y-\frac{F}{\alpha}
$$

Under unification the partial derivative of utility with respect to location is:

$$
\frac{\partial U_{I}(i)}{\partial i}=g a, \quad \forall i \in[0, \alpha]
$$

Under separation this partial derivative is:

$$
\frac{\partial U_{I I}(i)}{\partial i}=g a, \quad \forall i \in\left[0, \frac{\alpha}{2}\right]
$$

Hence utility is linearly increasing at the same rate with respect to the location of an individual $i$ both in case of separation and unification. Therefore, when the individual at location $\alpha / 2$ prefers separation (unification) all the individuals in the interval $[0, \alpha / 2]$ are in favour of separation (unification). The continuity of the utility function in $i$ implies that the individuals sufficiently close to the individual located at $1 / 2$ prefer separation (unification) when the individual located at $1 / 2$ prefers separation (unification). Hence there will be a majority in favour of separation (unification).

A similar argument holds for region B.

Proof of Proposition 3: In the socially optimal solution the sum of all individual utilities is maximized. If it is optimal to have just one country, then it will be socially optimal to choose the location of the public good and the tax level to maximize:

$$
U_{I}=\int_{0}^{1} U_{I}(i) d i=g\left(1-a E\left(d_{i} \mid l\right)\right)+y-E\left(t_{i}\right)
$$

and if it is optimal to form two governments then it will be socially optimal to choose the location of the public good and the tax level to maximize:

$$
U_{I I}=\int_{0}^{1} U_{I I}(i) d i=\sum_{x=A, B} s_{x}\left[g\left(1-a E_{x}\left(d_{i} \mid l_{x}\right)\right)+y-E_{x}\left(t_{i}\right)\right]
$$

where $E_{x}\left(d_{i} \mid l_{x}\right), s_{x}$ and $E_{x}\left(t_{i}\right)$ are, respectively, the average distance in country $x$ given the location of the government, the size of country $x$ and the lump sum 
tax level in country $x$. Since the value of $\alpha$ is exogenously specified, the values of $s_{A}$ and $s_{B}$ are $\alpha$ and $1-\alpha$, respectively. In order to minimize $E_{x}\left(d_{i}\right)$ it is socially optimal to locate the government in the middle of each country. Hence, $E_{A}\left(d_{i}\right)$, $E_{B}\left(d_{i}\right)$ and $E\left(d_{i}\right)$ are, respectively, $\alpha / 4,(1-\alpha) / 4$ and $1 / 4$. Each country has to finance its own government, therefore $E_{A}\left(t_{i}\right), E_{B}\left(t_{i}\right)$ and $E\left(t_{i}\right)$ are, respectively, $F / \alpha, F /(1-\alpha)$ and $F$. Hence, the social utility expressions (22) and (23) can be rewritten as follows:

$$
\begin{gathered}
U_{I}=g\left(1-\frac{a}{4}\right)+y-F \\
U_{I I}=\alpha\left[g\left(1-a \frac{\alpha}{4}\right)\right]+(1-\alpha)\left[g\left(1-a \frac{1-\alpha}{4}\right)\right]+y-2 F
\end{gathered}
$$

Comparing the total utilities under union and separation determines the choice for either union or separation. It is better to have one government (one nation) if and only if $U_{I}>U_{I I}$ :

$$
g\left(1-\frac{a}{4}\right)+y-F>\alpha\left[g\left(1-a \frac{\alpha}{4}\right)\right]+(1-\alpha)\left[g\left(1-a \frac{1-\alpha}{4}\right)\right]+y-2 F
$$

After rearranging terms, this inequality can be written as

$$
\frac{g a}{2} \alpha^{2}-\frac{g a}{2} \alpha+F>0
$$

and this is equivalent with

$$
\alpha^{2}-\alpha+\frac{2 F}{g a}>0
$$

Note that this inequality will only have solutions if $F<g a / 8=F_{S P}$.

Inequality (26) is satisfied for values of $\alpha$ when:

$$
\alpha<\frac{1}{2}-\sqrt{\frac{1}{4}-\frac{2 F}{g a}}
$$

or when

$$
\alpha>\frac{1}{2}+\sqrt{\frac{1}{4}-\frac{2 F}{g a}}
$$

Note that the right hand side of inequality (30) is greater than $1 / 2$. Because $\alpha$ is, by assumption, smaller than $1 / 2$, we can omit inequality (30). This proves Proposition 3.

Proof of Lemma 2: Using the arguments of the proof of Lemma 1 we have to 
show that the partial derivative of utility under unequal union with respect to the location of the individuals is equal to the partial derivatives of utility under separation and unification on the $[0, \alpha / 2]$ interval. The utility function of an individual $i$ with respect to his location $i$ under unequal union is:

$$
U_{u u}(i)=g\left(1-a\left|\frac{\alpha}{2}+\frac{1}{2}-i\right|\right)+y-F
$$

Then the partial derivative of utility with respect to location is:

$$
\frac{\partial U_{u u}(i)}{\partial i}=g a, \quad \forall i \in\left[0, \frac{\alpha}{2}\right]
$$

Hence utility is linearly decreasing by the same rate with respect to the preference distance in case of separation, unification and unequal union. Therefore, when the individual at location $\alpha / 2$ prefers unequal union all the individuals in the interval $[0, \alpha / 2]$ are in favour of unequal union. The continuity of the utility function in $i$ implies that the individuals sufficiently close to the individual located at $1 / 2$ prefer unequal union when the individual located at $1 / 2$ prefers unequal union. Hence there will be a majority in favour of unequal union.

A similar argument holds for region B.

\section{Appendix B.}

One of the assumptions in the basic model is that the initial endowment per individual is equal in both regions. Wealth differences in, for example, Belgium between Flanders and Wallonia, between north and south Italy and between Norway and the European Union, however, have an influence on the incentives for union and separation in these regions. To study wealth differences across regions we write the initial endowment of the individuals in region $\mathrm{A}$ and in region $\mathrm{B}$ as $y_{A}$ and $y_{B}$, respectively. We suppose that these incomes differ by a factor $\theta, \theta>0$, and we write $y_{B}=\theta y_{A}$. It can be verified that wealth differences do not matter when the public good is financed by lump sum taxes. We therefore change the system of taxation to proportional taxes. When both regions separate there are different tax levels in each region and when there is union we have one tax level to finance the public good. One justification for this assumption is that a difference in tax-levels between the regions is not sustainable when the 
subject of taxation (e.g. capital or labour) is mobile in a union. If there exists a tax difference between the regions in a union then the capital or the labour will be located in the region with the lowest tax level. It is also possible that the legislation of a union allows just one tax rate. This leads to three proportional tax levels: $t_{A}$ denotes the tax level under separation in region $\mathrm{A}, t_{B}$ the same in region $\mathrm{B}$ and $t$ denotes the proportional tax level in a union. Recall that Proposition 1 tells us that there exists an $\alpha_{A}$ such that region A prefers union if and only if $\alpha \in\left(0, \alpha_{A}\right)$ and there exists an $\alpha_{B}$ such that region $\mathrm{B}$ prefers union if and only if $\alpha \in\left(\alpha_{B}, 1 / 2\right)$.

Proposition 8. When $\theta$ increases, $\alpha_{A}$ and $\alpha_{B}$ will increase. For $\theta>8 F /(8 F-$ ga) region $A$ always prefers union and for $\theta<(8 F-g a) / 8 F$ region $B$ always prefers union.

This Proposition is in line with the idea that it is more attractive to unite with a rich region than with a poor region: An increase in $\theta$ implies that the individuals in region $\mathrm{B}$ become relatively richer compared to the individuals in region $\mathrm{A}$. Union becomes therefore more attractive for region $\mathrm{A}$ and less attractive for the individuals in region $\mathrm{B}$, which is reflected by the increases in $\alpha_{A}$ and $\alpha_{B}$, respectively.

Proof of Proposition 8: Note that we can use Lemma 1 in this proof. We will prove that an increase in $\theta$ leads to an increase in $\alpha_{A}$. The proof that an increase in $\theta$ leads to an increase in $\alpha_{B}$ has the same structure as in the $\alpha_{A}$-case and it is therefore not given. Recall that we restricted $\alpha$ to values between 0 and $1 / 2$. The utility of individual $\alpha / 2$ under union is

$$
U_{I}\left(\frac{\alpha}{2}\right)=g-\frac{g a}{2}+\frac{g a \alpha}{2}+y_{A}-\frac{F}{(\alpha+(1-\alpha) \theta) y_{A}} y_{A}
$$

and under separation

$$
U_{I I}\left(\frac{\alpha}{2}\right)=g+y_{A}-\frac{F}{\alpha}
$$

Let $U_{I}^{\theta}(\alpha)$ and $U_{I I}^{\theta}(\alpha)$ be the utility of individual $\alpha / 2$ under union and separation, respectively. Like in the standard model, define $\alpha_{A}(\theta)$ as

$$
\begin{aligned}
& U_{I}^{\theta}(\alpha)<U_{I I}^{\theta}(\alpha) \text { for } \alpha<\alpha_{A}(\theta) \\
& U_{I}^{\theta}(\alpha)=U_{I I}^{\theta}(\alpha) \text { for } \alpha=\alpha_{A}(\theta) \\
& U_{I}^{\theta}(\alpha)>U_{I I}^{\theta}(\alpha) \text { for } \alpha>\alpha_{A}(\theta)
\end{aligned}
$$


Hence, since $U_{I}^{\theta}(\alpha)$ and $U_{I I}^{\theta}(\alpha)$ are differentiable in $\alpha$ for $\alpha \in(0,1 / 2)$

$$
\frac{\partial\left[U_{I}^{\theta}\left(\alpha_{A}(\theta)\right)-U_{I I}^{\theta}\left(\alpha_{A}(\theta)\right)\right]}{\partial \alpha}<0
$$

Next note that at $\alpha_{A}(\theta), U_{I}^{\theta}(\alpha(\theta))-U_{I I}^{\theta}(\alpha(\theta))=0$. Hence,

$$
\frac{\partial\left[U_{I}\left(\alpha_{A}(\theta)\right)-U_{I I}\left(\alpha_{A}(\theta)\right)\right]}{\partial \alpha} d \alpha+\frac{\partial\left[U_{I}\left(\alpha_{A}(\theta)\right)-U_{I I}\left(\alpha_{A}(\theta)\right)\right]}{\partial \theta} d \theta=0
$$

This implies that

$$
\frac{d \alpha_{A}(\theta)}{d \theta}=\frac{-\frac{\partial\left[U_{I}^{\theta}\left(\alpha_{A}(\theta)\right)-U_{I I}^{\theta}\left(\alpha_{A}(\theta)\right)\right]}{\partial \theta}}{\frac{\partial\left[U_{I}^{\theta}\left(\alpha_{A}(\theta)\right)-U_{I I}^{\theta}\left(\alpha_{A}(\theta)\right)\right]}{\partial \alpha}}
$$

Note that $\partial U_{I I}^{\theta}\left(\alpha_{A}(\theta)\right) / \partial \theta=0$,

$$
\frac{\partial U_{I}^{\theta}(\alpha)}{\partial \theta}=\frac{F(1-\alpha)}{(\alpha+(1-\alpha) \theta)^{2}}>0
$$

and recall that

$$
\frac{\partial\left[U_{I}^{\theta}\left(\alpha_{A}(\theta)\right)-U_{I I}^{\theta}\left(\alpha_{A}(\theta)\right)\right]}{\partial \alpha}<0
$$

Hence $d \alpha_{A}(\theta) / d \theta>0$. This completes the proof.

Proposition 9. The socially desirable outcome does not change when the endowments across regions vary.

Proof: In a social optimum the sum of all individual utilities is maximized. The utility under union is

$$
U_{I}=\int_{0}^{1} U_{I}(i) d i=\sum_{x=A, B} s_{x}\left[g\left(1-a E\left(d_{i} \mid l\right)\right)+y_{x}-t_{x} y_{x}\right]
$$

This implies that

$$
U_{I}=g\left(1-a E\left(d_{i} \mid l\right)\right)+y-\sum_{x=A, B} s_{x} t_{x} y_{x}=g\left(1-\frac{a}{4}\right)+y-F
$$

The utility under separation is

$$
U_{I I}=\int_{0}^{1} U_{I I}(i) d i=\sum_{x=A, B} s_{x}\left[g\left(1-a E\left(d_{i} \mid l\right)\right)+y_{x}-t_{x} y_{x}\right]
$$


So total utility under separation can be written as

$$
U_{I I}=\alpha\left[g\left(1-a \frac{\alpha}{4}\right)\right]+(1-\alpha)\left[g\left(1-a \frac{1-\alpha}{4}\right)\right]-2 F
$$

These utilities are equal to the utilities of equations 24 and 25. We can therefore apply the same analysis as in the standard model.

This Proposition implies that differences in initial endowments across regions are irrelevant for the socially optimal outcome in which aggregate utility is maximized. Moreover, the possibility of choosing different taxation systems for compensation or for wealth transfers does not influence the the socially desirable outcome. 


\section{References.}

1. Alesina, A. and R. Perotti, 1995, Economic and political risk in fiscal unions, NBER Working Paper No. 4992, January

2. Alesina, A., R. Perotti and E. Spolaore, 1995, Together or seperately? Issues on the costs and benefits of political and fiscal unions, European Economic Review, Papers and Proceedings, April, p. 751-758

3. Alesina, A. and E. Spolaore, 1995b, International conflict, defense spending, and the size of countries, mimeo, Harvard University

4. Alesina, A. and E. Spolaore, 1997, On the number and size of nations, Quarterly Journal of Economics, November, p. 1027-1056

5. Austin, D. A., 1993, Coordinated action in local public goods models: The case of secession without exclusion, mimeo, University of Texas

6. Benabou, R., 1993, Workings of a city: Location, education and production, Quarterly Journal of Economics, 108, p. 619-652

7. Benabou, R., 1995, Equity, efficiency, and human capital investment: The local connection, mimeo, NYU

8. Bewley, T. F., 1981, A critique of Tiebout's theory of local public expenditures, Econometrica 49

9. Bolton, P. and G. Roland, 1993, The break-up of nations: A political economy analysis, Quarterly Journal of Economics, November, p. 1057-1089 
10. Bolton, P., G. Roland and E. Spolaore, 1996, Economic theories of the break-up and integration of nations, European Economic Review (40), p. 697-705

11. Bookman, M. Z., 1993, The Economics of Secession, The Macmillan Press Ltd, London

12. Casella, A. and J. Feinstein, 1990, Public goods in trade: On the formation of markets and political jurisdictions, Working Paper in Economics E-9212, The Hoover Institution, Stanford University, May

13. Epple, D. and T. Romer, 1991, Mobility and Redistribution, Journal of Political Economy, 99(4)

14. Epple, D., R. Filimon and T. Romer, 1984, Equilibrium among local jurisdictions: Toward an integrated treatment of voting and residential choice, Journal of Public Economics 24

15. Fernandez, R. and R. Rogerson, 1994, Public education and income distribution: A quantative evaluation of education finance reform, NBER Working Paper No. 4883, October

16. Jehiel, P., and P. Scotchmer, 1995, On the right of exclusion in jurisdiction formation, June, CERAS and Berkeley

17. Musgrave, R., 1959, The theory of public finance, (McGraw-Hill, New York)

18. Oates, W.E., 1972, Fiscal federalism, (Harcourt Brace Jovanovich, New York) 
19. Persson, T. and G. Tabellini, 1992, Federal fiscal constitutions, Part I: Risk sharing and moral hazard, mimeo, Stockholm University

20. Persson, T. and G. Tabellini, 1993, Federal fiscal constitutions, Part II: Risk sharing and redistribution, Working Paper No. 61, IGIER, Milan, March

21. Persson, T. and G. Tabellini, 1994, Does centralization increase in the size of government?, European Economic Review, Papers and Proceedings, April

22. Rubinfeld, D. L., 1987, The economics of the local public sector, in: A. J. Auerbach and M. Feldstein, eds., Handbook of public economics, Vol. 2, ch. 11 (North-Holland, Amsterdam)

23. Scotchmer, S., 1996, Public Goods and the invisible hand, in: J. Quigley and E. Smolensky, eds., Modern public Finance (Harvard University Press, Cambridge, MA)

24. Tiebout, C., 1956, A pure theory of local expenditure, Journal of Political Economy 64

25. Stahl, K. and P. Varaiya, 1983, Local collective goods: A critical re-examination of the Tiebout model, in: J. F. Thisse and H. G. Zoller. eds., Locational analysis of public facilities (North-Holland, Amsterdam)

26. The Times Atlas of the World, Comprehensive Edition, Times Book, 1993, London 
27. Wei, S, 1991a, To Divide or to unite: A theory of secessions, mimeo, University of California at Berkeley

28. Wei, S, 1991b, Federation or commonwealth: A viable alternative to secessions?, mimeo, University of California at Berkeley

29. Wildasin, D., 1988, Nash equilibria in models of fiscal competition, Journal of Public Economics 35 